\title{
SILENCIAMENTO DOS SENTIDOS: USO DO TEXTO LITERÁRIO APENAS PARA ENSINO DE GRAMÁTICA
}

\author{
Francisco Neto Pereira Pinto* \\ Hilda Dutra Gomes Magalhães**
}

\begin{abstract}
RESUMO: Nosso objetivo consiste em analisar, sob a ótica dos estudos do letramento literário, uma unidade do livro didático alfabetização: série Brasil, de Bonini (2007). Para tanto, assumimos como conceito de letramento literário o desenvolvimento de habilidades indispensáveis à formação do leitor de literatura tais como a percepção estética, a sensibilidade e a imaginação. Durante a análise da cartilha, percebemos, entretanto, que o texto literário foi utilizado mais como instrumento para facilitar a aquisição da habilidade de reconhecimento do código linguístico e a decifração de caracteres do que para se alargar a sensibilidade a explorar a construção de sentido, o que caracteriza uma exploração inadequada desse gênero textual na escola.
\end{abstract}

PALAVRAS-CHAVE: Direito à literatura - Letramento literário - Livro didático

\begin{abstract}
Our objective consists of analysing one primer from the perspective of literary literacy studies.The book studied was from the series Brasil by Bonini(2007). For this purpose, we assume as literary literacy concept the development of indispensable abilities to become a literature reader, such as the aesthetic perception and the sensitivity and imagination developed. During the analysis of the primer, we realized,however, that the literary text was used more like an instrument to facilitate the acquisition of the ability to recognize the linguistic code and its decoding than to broaden the sensitivity and exploit the meaning construction, which characterizes an inadequate exploitation of this textual genre taught as they do at Basic schools.
\end{abstract}

KEY-WORDS: Right to Literature - Literary Literacy - Didactic Book

Se, por motivo qualquer, no teatro do ensino, todos os atores fossem expulsos em detrimento de um só, esse deveria ser, certamente, como único a encenar no palco, a literatura. Essa defesa da disciplina literária nos remete, sem dúvidas, a Barthes que a justifica dizendo que "todas as ciências estão presentes no monumento literário". (BARTHES, 1978, P. 18).

Não é sem razão que assim se posiciona o autor, pois, como explica Cândido (1995, p. 242), a literatura é indispensável à vida do homem e, portanto, não há homem que possa viver sem ela, quer seja ele de formação acadêmica ou não. Tal é sua

\footnotetext{
Mestrando em Ensino de Língua e Literatura pelo Programa de Pós-Graduação Letras da Universidade Federal do Tocantins, campus de Araguaína. / fneto@uft.edu.br.

* Doutora em Teoria Literária, com pós-doutorado na Universidade de Paris III e na École des Hautes Études em Sciences Sociale; Prof ${ }^{a}$. do Curso de Letras, Campus de Araguaína, Universidade Federal de Tocantins, UFT. / hildadutra@uft.edu.br
}

Cadernos do IL. Porto Alegre, n. ${ }^{\text {o } 38, ~ j u n h o ~ d e ~ 2009 . ~ p . ~ 88-97 . ~}$ http://www.seer.ufrgs.br/cadernosdoil/ 
importância que o acesso a ela é garantido pela Declaração Universal dos Direitos Humanos de 1948, no parágrafo 1, quando diz: "toda pessoa tem o direito de participar livremente da vida cultural da comunidade, de fruir as artes e de participar do processo científico e de seus benefícios". É bem verdade que este artigo não faz referência direta à literatura, mas reporta-se à fruição das artes, o que, sem dúvida, inclui a literatura e, neste ínterim, acreditamos que de forma bem especial.

Para Hegel (1997:20), a arquitetura, a escultura, a pintura, a música e a poesia "formam o sistema definido e articulado da arte real e efetiva" e, embora afirme que existam outras artes além destas, como a dança, a arte dos jardins etc, o autor as tomam como artes incompletas. No entanto, no sistema das artes de Hegel, a poesia se coloca como a verdadeira arte absoluta, uma arte total e, nas palavras do autor, "a poesia é, pelo seu conteúdo, de todas as artes a mais rica, a mais ilimitada" (HEGEL, 1997:19). Do agora dito, acreditamos que a referida Declaração assegura bem, então, o acesso à literatura como um bem universal do ser humano.

A literatura, então, como direito universal humano, que há muito foi incorporada ao currículo escolar no ensino secundário, enquanto área de ensino (BARTHES, 1978), e tem tido seu lugar institucional garantido, no ensino básico, no Brasil, por diplomas legais, quer como disciplina, quer como gênero discursivo ou textual (OLIVEIRA, 2008), pois é na escola que "se aprende a ler e escrever, conhece-se literatura e desenvolve-se o gosto de ler" (ZILBERMAN, 1988:10).

A escola, entretanto, enfrenta muitas dificuldades na formação de leitores de textos literários, o que se deve, em partes, a uma deficiência teórico-metodológica sobre ensino da literatura, que se manifesta, principalmente, na forma como a leitura literária é trabalhada no livro didático, posto que, conforme Zilberman (2005), ele é o portador mais credenciado da tradição literária e acaba por impor "uma concepção de leitura e consumo de criações literárias" (ZILBERMAN, 2005:249). Isto posto, nosso objetivo no presente texto é analisar uma unidade do livro didático Alfabetização: série Brasil, de Bonini (2007), distribuída às escolas públicas pelo MEC e faremos isso sob a ótica do que Rangel (2005) e Cosson (2007) chamam de letramento literário, buscando refletir sobre a adequação do tratamento dado ao texto literário na referida cartilha.

Estudos envolvendo questões do letramento, no Brasil, remontam à década de 1980 e contam com expressivos trabalhos desenvolvidos na área (SOARES, 2001; (KLEIMAN, 2001; TFOUNI, 2005, entre outros). O letramento, de modo geral, pode ser definido como "conjunto de práticas sociais que usam a escrita enquanto sistema simbólico e enquanto tecnologia, em contextos específicos, para objetivos específicos" (KLEIMAN, 2001, p. 19). Depreende-se dessa definição que o letramento é relacionado com os usos efetivos que o sujeito é capaz de realizar, em um nível satisfatório, que é definido socialmente, e aí considera-se cada caso em sua especificidade, com a escrita, não apenas como tecnologia, mas também em nível discursivo. Em outras palavras, ser letrado significa "viver no mundo da escrita, dominar os discursos da escrita, ter condições de operar com os modos de pensar e produzir da cultura escrita" (BRITTO, 2005:13).

Cadernos do IL. Porto Alegre, n. ${ }^{\text {o } 38, ~ j u n h o ~ d e ~ 2009 . ~ p . ~ 88-97 . ~}$ http://www.seer.ufrgs.br/cadernosdoil/ 
O processo de letramento literário, que se realiza mediante usos de textos literários, engloba não apenas o uso social da escrita em uma dimensão diferenciada, "mas também, e sobretudo, uma forma de assegurar seu domínio" (COSSON, 2007:12). Assim, um sujeito literariamente letrado seria aquele que cultivasse e assumisse como parte de sua vida o texto literário, "preservando seu caráter estético, aceitando o pacto proposto e resgatando objetivos culturais em sentido mais amplo, e não objetivos funcionais ou imediatos para seu ato de ler" (PAULINO, 2001:118).

Mas em que consiste, então, a relevância do letramento literário? A literatura, como se sabe, "é um objeto estético" (CULLER, 1999, P. 40) e, como tal, sua mais nobre função é a de causar prazer e esse é um "tipo especial de prazer, que é o sentimento estético. O que a literatura proporciona ao leitor, só ela o faz, e esse prazer não pode ser confundido com nenhum outro" (COUTINHO, 2008:23).

Resumindo essa ideia, Aguiar (2007, p. 18) afirma que "a arte literária é o espaço da imaginação, do lúdico, da liberdade". Por esta linha de raciocínio, podemos ser levados a imaginar que a leitura literária privilegia apenas a fruição. Não obstante, como adverte Pereira (2007, p. 33), o letramento literário "também requer dos sujeitos envolvidos em seu processo de ensino-aprendizagem níveis de reflexão cada vez mais dinâmicos e complexos". Além disso, uma vez que, no primeiro plano, está o estético para a literatura, secundariamente ela pode se prestar a outras tarefas, pois como nos ensina Coutinho (2008:23), a literatura "não visa a informar, ensinar, doutrinar, pregar, documentar. Acidentalmente, secundariamente, ela pode fazer isso".

Afinal, como declara Cosson (2007, p. 26), "no ambiente escolar, a literatura é um lócus de conhecimento e, para que funcione como tal, convém ser explorada de maneira adequada. A escola precisa ensinar o aluno a fazer essa exploração". Ainda de acordo com o autor, cabe ao professor, sob a ótica do letramento literário, "explorar ao máximo, com seus alunos, as potencialidades desse tipo de texto" (COSSON, 2007, p. 29). Do já posto, queremos dizer que entendemos que o letramento literário não se reduz ao reconhecimento dos aspectos composicionais que o texto literário oferece. Ele tem que ver com um manejo em um nível mínimo satisfatório de um texto que, por natureza, é plurissignificativo e que dialoga com a sensibilidade, com o imaginário, com a subjetividade e com o social.

Compreende-se daí que a leitura advogada pelo letramento literário avança para além da aquisição da habilidade de reconhecer o código linguístico e a decifração de caracteres sob os quais se erige o sentido. Ela busca no leitor o refinamento da sensibilidade, da percepção estética, do conhecimento de si mesmo e do mundo e da ampliação das fronteiras do imaginário e da subjetividade, compreendidas aqui também como instrumentos de produção de saberes.

Com base nessas considerações, procederemos a uma análise do tratamento dado ao poema Hap da limpeza, de Patrícia Engel Secco, na cartilha Alfabetização: série Brasil, de Luci Mendes de Melo Bonini, distribuída às escolas públicas desde 2004. O poema mencionado é sugerido como atividade de leitura e está inserido no capítulo que tem como tema Viva a natureza!. Ao professor é dada a instrução de que deve, a partir do referido capítulo, refletir com os alunos sobre algumas questões ambientais, tais

Cadernos do IL. Porto Alegre, n. ${ }^{\text {o } 38, ~ j u n h o ~ d e ~ 2009 . ~ p . ~ 88-97 . ~}$ http://www.seer.ufrgs.br/cadernosdoil/ 
como lixo, reciclagem, preservação animal e vegetal etc. Ademais, o comando insta que o professor procure saber qual o posicionamento dos alunos em relação ao assunto e se eles recebem orientações em casa no que diz respeito ao mesmo.

O poema hap da limpeza é composto por duas estrofes, de oito versos cada uma. A primeira estrofe está alinhada à margem esquerda do livro e a segunda, que tem seu primeiro verso à altura do penúltimo verso da primeira estrofe, à margem direita. Abaixo da primeira estrofe e acima da segunda, há uma gravura de um menino e uma menina, respectivamente. Em cada gravura há, ainda, uma cesta, identificada com o nome lixo. Na primeira gravura pode-se ainda destacar um passarinho, que voa à altura da cabeça do garoto. No canto superior da página, do lado esquerdo, há uma gravura que figurativiza uma paisagem natural, ao que parece ainda intocada, ou, ao menos, em bom estado de conservação, quer dizer, não transformada pela ação humana. A paisagem é de uma cachoeira cujas águas, amortecidas pela queda, correm pelo curso que se desenha por entre o verde da vegetação ali presente.

Como atividade exploratória do poema, sob o subtítulo cantando hap, a primeira questão propõe que o aluno se reúna com alguns colegas da sala para inventar um ritmo e cantar o hap. A seguir, os grupos poderão se apresentar para a classe. De nossa parte, consideramos que a atividade proposta é salutar e desejável, pois propicia o diálogo entre manifestações artísticas diferentes que têm nas suas especificidades a possibilidade de estímulo à imaginação e de respeito às idiossincrasias. É a interpretação de um objeto artístico por outra linguagem artística, cujo resultado já é, em si, um outro objeto, posto ser uma recriação, configurando o que Corrêa e Martins (2007, p. 7) chamam de "novos modos de ler a literatura na contemporaneidade".

Sabemos que, entre poesia e música, o diálogo é estreito, dado o fato de que a sonoridade é um dos aspectos que deve ser levado em consideração quando o poema o reclama, o que é o caso do texto em tela e, talvez não por acaso, o estilo musical escolhido tenha sido o hap, que se coloca muito apropriado para a exploração do efeito de sentido que propicia as rimas do poema. Desse modo, uma educação literária, ainda que elementar, do ponto de vista do letramento literário, deveria levar em consideração, antes do diálogo com a música, algo como leituras ritmadas do poema, o que poderia possibilitar o desfrute, em um primeiro plano, do próprio objeto literário e, posteriormente, o conhecimento desse tipo de gênero que os alunos poderiam generalizar quando em face de outros poemas. Não é isso que gera os gêneros, padrões de expectativas? Saber ler conforme exige os gêneros não faz parte das exigências de um leitor minimamente iniciado no processo de letramento? Eis, pois, o porquê de nossa defesa de atividades exploratórias próprias à natureza do objeto literário em um primeiro momento para, só depois, o uso do artefato para ensino de gramática, ou, leiase, atividades linguísticas.

Das oito questões que compõem a unidade, a atividade acima destacada é a única que se propõe, ainda que timidamente, a reservar ao poema o olhar que lhe é devido, nos termos do letramento literário. De resto, para todas as demais questões, com exceção da penúltima, como diz Aguiar (2007, p. 20), "a literatura converte-se em material para exercícios gramaticais (...) o que ela não é". Não é nosso objetivo aqui

Cadernos do IL. Porto Alegre, n. ${ }^{\text {o } 38, ~ j u n h o ~ d e ~ 2009 . ~ p . ~ 88-97 . ~}$ http://www.seer.ufrgs.br/cadernosdoil/ 
verificar se o modo como as atividades linguísticas são propostas condizem ou não com os estudos do letramento e com as mais recentes orientações para o ensino da língua portuguesa e suas variantes, mas reconhecemos que o uso do texto literário como objeto sobre o qual incide tais atividades cumpre a um objetivo desejável, para essas atividades, qual seja, torná-las contextualizadas e, portanto, significativas.

Porém, se é assim para as atividades linguísticas, o mesmo não se dá no trato que se espera para com o texto literário. Não é uma questão de sacralizar a literatura e procurar separá-la, enquanto artefato cultural, da sociedade, tampouco queremos elevála acima dos demais gêneros textuais e discursivos. O que queremos destacar é que, confirme já sublinhamos, a literatura hoje entra na escola não mais, obrigatoriamente, como disciplina separada; às vezes é como gênero textual ou discursivo que ela assegura sua presença aí nesse espaço e o livro didático se apresenta, nesse caso, como seu principal veiculo de circulação. Se, pois, as atividades de leitura, escrita e linguística se realizam não dissociadas e na perspectiva do letramento, não seria de se esperar que o trabalho com a literatura também recebesse atenção adequada? Parece-nos que a resposta sinaliza no sentido de sim, pois do contrário não faria sentido hoje falarmos de letramentos.

Assim, debaixo do subtítulo descobertas, primeira questão, a cartilha apresenta atividades que trabalham a classe gramatical do substantivo, mais especificamente o primitivo e o derivado. Na segunda, é apresentada a menina que aparece na figura 1, no poema hap da limpeza!. O desafio proposto é que se descubra o nome da mesma a partir de pistas que são apresentadas, quais sejam, uma coluna na vertical e, paralela à cada linha, figuras de frutas, de insetos, de um doce e de uma pena. Cada letra do nome corresponde a um número ordinal. Então, nas linhas da coluna deve-se escrever a letra que corresponde ao ordinal indicado. Assim, ao final, haverá seis nomes e, consequentemente, a indicação de seis ordinais que, por sua vez, representam seis letras. Ao se preencher adequadamente os espaços na coluna, tem-se o nome Mariana. Ainda na mesma questão, um segundo questionamento versa sobre quantos nomes estão contidos no nome da menina, ou seja, de Mariana.

Semelhantemente, na terceira questão do mesmo subtítulo, a proposta é que se encontrem outras palavras escondidas sob nomes tais como parede, peruca, touro etc. Já na quarta questão, propõe-se a leitura, em voz alta, das palavras rato e tora. Deve-se, ainda, na sequência, escrever essas mesmas palavras e separá-las por sílabas. Posterior a isso, sugere-se a inversão das sílabas de cada palavra que, após lidas, evidenciarão a diferença sonora da letra $r$ em cada uma delas. A quinta questão propõe a leitura de palavras contidas em dois quadros distintos. O primeiro contém palavras iniciadas com a letra $r$ tais como: roda, rã, rádio e outras. No segundo, a letra $r$ comparece em todas as palavras, mas não em posição inicial, conforme exemplificado aqui em arara, jacaré e urubu. Após a leitura, o comando dado é no sentido de pintar a letra $r$ em todas as palavras que compõem os dois quadros.

Por fim, a penúltima questão, sob o subtítulo criação, sugere que, reunido com colegas, o aluno crie regras importantes para manter a limpeza da sala de aula ou da escola. A questão versa sobre os alunos passarem o texto a limpo em uma cartolina e

Cadernos do IL. Porto Alegre, n. ${ }^{\circ}$ 38, junho de 2009. p. 88-97. http://www.seer.ufrgs.br/cadernosdoil/ 
organizarem um mural na classe ou nos corredores da escola com as frases que criaram. Com respeito a essa última questão, percebe-se aí um olhar pedagogizante do fazer literário, uma prática muito comum nos livros didáticos e que leva o aluno a fazer interação entre o texto, o aluno e o contexto. É também atualizar a obra literária e colocá-la em diálogo com a sociedade. Pode-se afirmar, assim, com base em Faria (1999, p. 22), que essa atividade está em "consonância com o que preconizam os PCNs em relação aos temas transversais e ao que recomendam as DCNEF".

Entretanto, do ponto de vista do letramento, uma atividade que aliasse ao proposto algo que fizesse um apelo mais direto à imaginação e à sensibilidade teria mais valor do ponto de vista da criação de sentidos do literário para o aluno. A proposta poderia bem instruir que essas regras fossem elaboradas por meio de textos de criação livre, tal como poemas ou outros gêneros que resvalassem para atividades mais subjetivas e que levassem o aluno a criar novos sentidos para o texto, alargando a sensibilidade e a imaginação do leitor.

Do mesmo modo, assim como a sensibilidade é muito pouco trabalhada nas atividades propostas, em nenhum momento é chamada a atenção dos alunos quer para o aspecto estético, quer para o sociológico (ou outros) da obra literária, restringindo-se as questões a jogos mecânicos de reconhecimento de elementos linguísticos. Voltando à primeira questão, embora a tenhamos considerado apropriada, destacamos, porém, que o momento não era o oportuno. A questão é: em que medida o poema poderia ser recriado na atividade musical, uma vez que o texto não foi interpretado, explorado, enfim, colocado como objeto de análise?

Atividades não tão complexas, mas arrojadas a uma criança, como explorar o binômio grito/cochicho na constituição do sentido de importância de ouvir o grito da limpeza e/ou natureza já seria, em se tratando do texto literário, dar-lhe alguma consideração. Poder-se-ia, ainda, discutir de onde provém o grito, ou seja, quem é que, ao invés de cochichar, grita, no poema? Gritar poderia indicar mais urgência no tom de reclame da natureza, o passo que cochichar poderia amenizá-lo? Na prática, poder-se-ia pedir que um aluno cochichasse ao outro e, posteriormente, que o mesmo que foi dito ao ouvido fosse dito em forma de grito, do que restaria estabelecido o contraste e os efeitos de sentidos que se evidenciam entre gritar e cochichar.

Uma outra questão que se poderia explorar tem a ver com o modo de a mãe natureza agradecer pelo ato de limpar, pelo comportamento de limpeza empreendido e assumido, respectivamente, pelos sujeitos. Como as crianças percebem isso? Esse agradecimento em alguma medida se relacionaria com a figura da cachoeira no alto da página, que pode sugerir um meio ambiente preservado e saudável? Como destacamos acima, o poema hap da limpeza! é um texto sincrético, ou seja, embora manifestado por várias linguagens, provém de uma enunciação única que lhe confere unidade e, assim, o texto comparece como um todo de sentido. Em relação ao texto sincrético, Teixeira (2008, p. 172) afirma que esse é "um objeto que, acionando várias linguagens de manifestação, está submetido, como texto, a uma enunciação única que confere unidade à variação".

Cadernos do IL. Porto Alegre, n. ${ }^{\circ}$ 38, junho de 2009. p. 88-97. http://www.seer.ufrgs.br/cadernosdoil/ 
Do exposto, destacamos que o poema hap da limpeza! apresenta como materialidade que comporta potencial de provocação de sentido não apenas os elementos linguísticos, mas também os visuais que, com aqueles, compõem o texto. Mas, quer linguísticos, quer visuais, todos eles foram, em toda a unidade, desprezados, quando a questão é o trabalho voltado para a questão estética do texto. Não é uma questão de dizer que as outras atividades não tenham validade pelo fato de não estarem a serviço do estético, mas é uma afirmação que se funda no fato de o estético não ter sido levado em consideração e, mesmo quando uma questão ou outra se coloca como apropriada ao trabalho com o literário, não comparece como tal. Exemplo disso são as atividades que exploram o som da letra $r$ que, embora se possa colocar como atividade lúdica, não é efetuada de modo a relacioná-la com a construção rítmica do poema, o que despreza a possibilidade de uma educação literária.

Em adição, como as rimas que compõem o poema constroem a sonoridade do ritmo musical hap? Se exploradas, os alunos poderiam construir o ritmo para o hap com base no poema e daí o considerariam em alguma medida, ao invés de estarem inteiramente livres para inventar, como recomenda a primeira questão. De mais a mais, é inocência pensar em tal liberdade de invenção, pois como seres sociais que somos é bem provável que as crianças, que não são incentivadas a levarem em consideração o poema, construam o ritmo do poema, em grande parte, com base no que já conhecem desse estilo musical.

É bem verdade que considerarem a estrutura do poema ao comporem o ritmo do hap não os isentaria de considerarem o que já sabem sobre esse ritmo de música, o que, aliás, é desejável. Mas não é menos verdade que se daria a devida importância ao objeto literário posto ali como uma alteridade que merece e exige a devida consideração. Não fosse assim, qual o propósito de sua presença ali? Se não é para olhá-lo, é bem provável que um texto de outro gênero se prestasse com maior eficiência às atividades naquela unidade propostas.

Muitas são as possibilidades de análises do tratamento literário dado ao poema e não é objetivo deste estudo esgotá-las. Mas, do exposto, pode-se concluir que, na cartilha em estudo, o poema hap da limpeza! não recebe o tratamento digno de ser dispensado a um objeto literário, isso quando consideramos que a cartilha é um instrumento didático que se presta ao ensino tanto da língua quanto da literatura, logo espera-se que o tratamento dispensando tanto a uma como a outra sejam coerentes com a natureza de cada uma em suas especificidades. Na unidade Viva a natureza, a única que analisamos, o artefato é negligenciado enquanto objeto artístico e comparece aí mais com o objetivo de ser utilizado apenas como objeto para ensino da gramática, ou para atividades linguísticas, e da escrita do que para formar, também, as habilidades que se esperam de um leitor de literatura.

Esse pedagogismo, como diz Faria (1999, p. 34), que insiste em transformar o texto de ficção em aulas de gramáticas só pode gerar resultados desastrosos, se se levar em consideração o letramento literário. A questão posta, destaque-se, não é que não se possa escolarizar a literatura, "mas sim como fazer essa escolarização sem descaracterizá-la, sem transformá-la em um simulacro de si mesma" (COSSON, 2007,

Cadernos do IL. Porto Alegre, n. ${ }^{\text {o } 38, ~ j u n h o ~ d e ~ 2009 . ~ p . ~ 88-97 . ~}$ http://www.seer.ufrgs.br/cadernosdoil/ 
P. 23). Negar em uma cartilha, instrumento de alfabetização, o tratamento devido que o objeto literário reclama se coloca, ao nosso ver, de acordo com Paulino (2005, p. 15), uma falta de ética. A questão aí é: trata-se de uma cartilha distribuída pelo MEC às escolas, espaço formal de estudo, instituição responsável por formação de leitores e, neste caso, formação inicial. Iniciar desse modo não seria ter um direito negado, o direito à literatura?

Talvez aí esteja uma das causas de os alunos estarem mais despreparados para ler textos literários, "apesar do empenho representado pelas diretrizes curriculares, pelas normas institucionais, pelas escolas e pelos incansáveis professores", como afirma Brait (2005, p. 8). Compreender essa realidade e redimensionar as práticas de leituras literárias na sala de aula, com atividades que realmente demandem do aluno o investimento da sensibilidade, da imaginação e da subjetividade é o que se espera que a escola faça, sobretudo na Alfabetização.

Mas, para isso, precisamos sempre ter em mente que o estético se liga não à objetividade, mas à subjetividade, pois como diz Kant (2010:32) "aquilo que na representação de um objeto é meramente subjetivo, isto é, aquilo que constitui a sua relação com o sujeito e não com o objeto é a natureza estética dessa representação". Importante também não esquecer que a matéria prima da literatura é a fantasia, pois, como diz Hegel (1997:374) "formar e dizer, segundo a fantasia, sem descrever as coisas na respectiva existência prática, tal é, com efeito, a missão da poesia". Fantasia, eis algo que as crianças têm em abundância! A elas, então, muito a poesia tem a dizer.

\section{REFERÊNCIAS:}

AGUIAR, Vera Teixeria de. Literatura e educação: diálogos. In: PAIVA, Aparecida et al. Literatura: saberes em movimento. Belo Horizonte: Autêntica, 2007. p. 17-27.

KANT, Immanuel. Crítica da faculdade do juízo. Tradução de Valerio Rohden e António Marques. 2 ed. Rio de Janeiro: Forense Universitária, 2010.

KLEIMAN, Angela. Modelos de letramento e as práticas de alfabetização na escola. In: KLEIMAN, Angela. (Org.) Os significados do letramento: uma nova perspectiva sobre a prática social da escrita. 3 reimpr. Campinas: Mercado de Letras, 2001. p. 15-61.

BARTHES, Roland. Aula. Trad. de Leyla Perrone-Moisés. São Paulo: Cultrix, 1978.

BONINI, Luci M. de Melo. Alfabetização. 1 ed. 2 reimpr. São Paulo: Ática, 2007.

BRAIT, Beth. A escola ainda tem lugar para a formação de leitores competentes? In: CEREJA, Willian Roberto. Ensino de literatura: uma proposta dialógica para o trabalho com literatura. São Paulo: Atual, 2005. Prefácio.

BRITTO, Luiz Percival Leme. Letramento e alfabetização: implicações para a educação infantil. In: FARIA, Ana Lúcia Goulart.; MELLO, Suely Amaral (Orgs.) O mundo da escrita no universo da pequena infância. Campinas: Autores Associados, 2005. p. 5-21.

CÂNDIDO, Antônio. O direito à Literatura. In: Vários escritos. São Paulo: Duas Cidades, 1995. p. 235-263.

Cadernos do IL. Porto Alegre, n. ${ }^{\text {o } 38, ~ j u n h o ~ d e ~ 2009 . ~ p . ~ 88-97 . ~}$ http://www.seer.ufrgs.br/cadernosdoil/ 
CHIARETTO, Marcelo. Literatura e educação: uma proposta de inclusão social a partir de Antonio Candido. In: XI Congresso Internacional da ABRALIC. São Paulo, 2008. Anais do XI Congresso Internacional da ABRALIC. São Paulo: Editora da Universidade de São Paulo (USP), 2008. v. 01. p. 10-12. Disponível in: http://www.abralic.org.br/cong2008/AnaisOnline/simposios/pdf/009/MARCELO_CHI ARETTO.pdf. Acessado em: 16/03/2009. COUTINHO, Afrânio. Notas de teoria literária. Petrópolis, RJ: Vozes, 2008.

COMPAGNON, Antoine. O demônio da teoria: literatura e senso comum. Trad. de Cleonice Paes Barreto Mourão, Consuelo Fortes Santiago. Belo Horizonte: UFMG, 2006.

COSSON, Rildo. Letramento literário: teoria e prática. 1 ed. 1 reimp. São Paulo: Contexto, 2007.

CORRÊA, Hércules; MARTINS, Aracy. O jogo dos saberes literários. In: PAIVA, Aparecida et al. Literatura: saberes em movimento. Belo Horizonte: Autêntica, 2007. p. 7-15.

CULLER, Jonathan. Teoria Literária: uma introdução. Trad. Sandra Vasconcelos. São Paulo: Beca Produções Culturais, 1999.

Declaração Universal dos Direitos Humanos. Traduzida por United Nations High Commissioner For Human Rights. Disponível in: www.comitepaz.org.br/.../Declaração \%20Universal\%20dos\%20Direitos\%20Humanos.pdf. Acessada em: 16/10/2009.

FARIA, Alice Maria. Parâmetros curriculares nacionais e literatura: as personagens de que os alunos realmente gostam. São Paulo: Contexto, 1999.

HEGEL, Georg Wilhelm Friedrich. Curso de estética: o sistema das artes. Tradução de Álvaro Ribeiro. São Paulo: Martins Fontes. 1997.

OLIVEIRA, Luiz Eduardo. O ensino de Literatura e a identidade nacional: o caso brasileiro. In: SANTOS, Josalba Fabiana dos; OLIVEIRA, Luiz Eduardo (orgs.) Literatura e Ensino. Maceió: EDUFAL, 2008, p. 27-42.

PAULINO, Graça. Livros, críticos, leitores: trânsitos de uma ética. In: PAIVA, Aparecida et al (Orgs). Literatura e Letramento - espaços, suportes e interfaces, o jogo do livro. Belo Horizonte: Autêntica, 2005. p. 13-20.

PEREIRA, M. Antonieta. Jogos de linguagem, redes de sentido: leituras literárias. In: PAIVA, Aparecida et al. Literatura: saberes em movimento. Belo Horizonte: Autêntica, 2007. p. 31-45.

RANGEL, Egon de Oliveira. Letramento literário e livro didático de língua portuguesa: os amores difíceis. In: PAIVA, Aparecida et al(Orgs). Literatura e Letramento- espaços, suportes e interfaces, o jogo do livro. Belo Horizonte: Autêntica, 2005. p. 127-146.

SOARES, Magda. Letramento: um tema em três gêneros. 2 ed. 3 reimpr. Belo Horizonte: Autêntica, 2001.

TEIXEIRA, Lucia . Achados e perdidos: análise semiótica de cartazes de cinema. In: LARA, Glaucia Muniz Proença; MACHADO, Ida Lucia; EMEDIATO, Wander (Orgs.) Análises do discurso hoje. 1 ed. Rio de Janeiro: Nova Fronteira, 2008, v. 1, p. 169-198. TFOUNI, Leda Verdiani. Letramento e alfabetização. 7 ed. São Paulo: Cortez, 2005.

Cadernos do IL. Porto Alegre, n..$^{\text {3 } 38, ~ j u n h o ~ d e ~ 2009 . ~ p . ~ 88-97 . ~}$ 
Cadernos do IL e Cadernos do IL o Cadernos do IL o Cadernos do IL o Cadernos do IL o Cadernos do IL

ZILBERMAN, Regina. Letramento literário: não ao texto, sim ao livro. In: PAIVA, Aparecida et al (Orgs). Literatura e Letramento - espaços, suportes e interfaces, o jogo do livro. Belo Horizonte: Autêntica, 2005. p. 245-266.

A leitura e o ensino da literatura. São Paulo: Contexto, 1988.

Cadernos do IL. Porto Alegre, n. ${ }^{\circ}$ 38, junho de 2009. p. 88-97.

http://www.seer.ufrgs.br/cadernosdoil/ 